\title{
Cardiac differentiation of bone marrow resident c- kit+ stem cells by L-carnitine increases through secretion of VEGF, IL6, IGF-1 and TGF- $\beta$
}

\section{Raheleh Farahzadi}

Ezzatollah Fathi ( $\square$ ez.fathi@tabrizu.ac.ir)

University of Tabriz https://orcid.org/0000-0003-0806-2735

Ilja Vietor

Sara Javanmardi

\section{Research}

Keywords: Bone marrow resident c-kit+ stem cells, Cardiac differentiation, Cell therapy, Cytokine secretion, L-carnitine

Posted Date: April 8th, 2020

DOI: https://doi.org/10.21203/rs.3.rs-21094/v1

License: (c) (i) This work is licensed under a Creative Commons Attribution 4.0 International License. Read Full License 


\section{Abstract}

Background: The idea of regenerating lost myocardium via cell therapies remains highly considerable. Also, C-kit+ stem/progenitor cells are represented to be suitable candidates for cardiac regeneration compared to other stem cells. A multitude of cytokines from these cells are known to give such multifunctional properties; however, associated mechanisms of these factors must still be absolutely understood. On the other hand, loss of cell survival and functionality, is one of the main problems in regenerative medicine. The aim of the present study was to investigate the in vitro effect of L-carnitine (LC) on cardiac differentiation of c-kit+ cells via cytokines secretion assay.

Methods: For this purpose, bone marrow resident-c-kit+ cells were enriched by MACS method, and were differentiated to cardiac cells in the absence (-LC) and presence of LC (+LC). Also, Characterization of enriched c-kit+ cells was performed using flow cytometry and immunocytochemistry. At the end of the treatment period, the cells were subjected to real-time PCR along with western blotting assay for gene and protein assessment, respectively. Then, culture medium was collected from both control (-LC) and experimental groups $(+\mathrm{LC})$ for cytokine array.

Results: It was found that $0.2 \mathrm{mM}$ LC induces cardiac differentiation of c-kit+ cells via increasing the cardiac markers expression of Ang-1, Ang-2, C-Tnl, VEGF, vWF, and SMA. Also, the significant presence of IL-6, IGF-1, TGF- $\beta$, and VEGF were obvious in the cultured media.

Conclusion: It can be concluded that in vitro effects of LC on cardiac differentiation of c-kit+ cells could be due to the secreted cytokines IL-6, IGF-1, TGF- $\beta$, and VEGF.

\section{Background}

Heart failure is the main cause of mortality worldwide. Dysfunctions of heart as well as significant reduction in cardiac myocytes are the eminent signs in acute myocardial infarction (AMI). Also, impotence of cardiomyocytes and insufficiency of healthy cardiomyocytes to compensate of heart function, have led to considerable attention for new therapeutic approaches [1, 2]. In other words, neovascularization and cardiac regeneration are important processes to rescue organ from acute ischemia $[3,4]$. Hence, finding suitable method/methods to recover cardiac cells after AMI is the final purpose at the heart research centers [5]. Recently, stem cells usage has been known as an attractive method, which could regenerate and repair the lost heart organ [6]. Nowadays, broadly used cells in the animal modeling are modeling that are somatic stem cells from various adult tissues, embryonic stem (ES) cells, and induced pluripotent stem (iPS) cells [7, 8]. As mentioned earlier, somatic stem cells-derived from various tissues such as adipose tissue, bone marrow (BM), and heart have been used to regenerate dead myocardium; however, its efficiency is low due to progressive loss of functional role and reduced output [9]. In addition, ES cells can effectively produce functional cardiomyocytes; however, due to retroviral gene transfer, the safety of ES cells as well as iPS cells is still controversial [10]. Among the cells used nowadays for cell therapy, endothelial progenitor cells (EPCs), and bone marrow-resident progenitor 
cells (BM-PCs) have been significantly contributed to myocardium regeneration, and were most widely tested in clinical trials [11]. Concerning the studies related to the impacts of BM-PCs on the heart, some contradictory effects have been reported on the left ventricle (LV) remodeling [12]. Apparently, it seems that the role of BM-PCs in cardiac regeneration and improvement are still controversial [13]. In other words, despite comprehensive research performed in the past 10 years, it is still unknown whether BMPCs are the best cell sources. Subsequent studies are required to investigate different types of these progenitor cells for the cell-based therapy in the heart failure. Among the BM-PCs, c-kit ${ }^{+}$hematopoietic stem cells (HSCs) are reported to have the most noteworthy recovery of cardiac after AMI [14]. Poor survival and retention of transferred cells into the pathologically damaged heart are widely accepted as significant barriers to enhance the efficacy of regenerative therapy. However, the use of external factors such as antioxidants to improve the cell survival properties is a favorite strategy for researchers. Lcarnitine (3-hydroxy-4-N-trimethylammoniumbutyrate) (LC) as an essential substance, plays an effective role in the mitochondria. Given the biological effect of $s$ of LC, it is considered to be important for supplying energy in the heart tissue. As reported earlier, heart failure is mostly along with reduction in ATP levels causing to insufficiency in mechanical work [15]. Therefore, LC has been considered to preserve cardiac function and cell viability [16]. Another identified effect of LC is increasing the flow of acyl/acetyl groups into the plasma, which plays an important role in the reduction of free radicals. Accumulation of these intermediates can lead to heart failure and ischemia [17]. Accordingly, we can hypothesize this point that LC as an endogenous antioxidant agent, could improve the potential of c-kit ${ }^{+} \mathrm{BM}$-resident stem cells in regenerative medicine via the greater cardiomyogenic differentiation of these cells. Also, in this research, we reported that increasing cardiomyogenesis of c-kit ${ }^{+}$cells in the presence of LC was correlated with the cytokine secretion. A general overview of methods steps was described as Graphical abstract.

\section{Results}

\section{Identification of BM-resident c-kit ${ }^{+}$cells}

As shown in Fig. 1, it was indicated that enriched BM-resident c-kit ${ }^{+}$cells by MACS had $89.8 \%$ expression of CD117 (c-kit) (Fig. 1A). Also, monitoring the protein level of c-kit-related marker in enriched c-kit + cells by ICC revealed the PE-conjugated CD117 (c-kit) cells (Fig. 1B).

\section{Cardiomyogenic Differentiation Confirmation Of BM- resident C-kit Cells By ICC}

The Cardiomyogenic differentiation was confirmed by ICC. In brief, as shown in Fig. 2 (A-D), the cardiomyogenic differentiated BM-resident $\mathrm{c}-\mathrm{kit}^{+}$cells were expressed the desmin and actinin as cardiomyogenic markers. 


\section{The effect of $\mathrm{LC}$ on the BM-resident c-kit ${ }^{+}$cells proliferation}

BM-resident c-kit ${ }^{+}$cells were treated with $0.1,0.2$ and $0.4 \mathrm{mM} \mathrm{LC}$ for 7,14 and 21 days and cell proliferation was examined by MTT assay [18]. In Fig. 3, the significance differences in BM-resident c-kit ${ }^{+}$ cells proliferation between the treated groups with $0.2 \mathrm{mM}$ of LC and the control group $(p<0.05)$ after 14 days was shown. In the other words, BM- resident c-kit ${ }^{+}$cells after 14 days treatment in the prescence of $0.2 \mathrm{mM}$ LC showed significantly more rapid growth than the 7and 21 days treatment $(* * P<0.01)$. For this reason, 14 days of incubation was the most suitable time for treatment of BM- resident c-kit ${ }^{+}$cells.

\section{Induction of gene and protein expression of cardiac markers in the BM- resident c-kit ${ }^{+}$cells in the presence of LC}

For evaluating the effect of LC on cardiomyogenic differentiation of BM- resident c-kit ${ }^{+}$cells, the mRNA and protein expression was examined. In this panel, Ang-1, Ang-2, C-Tnl, VEGF, vWF and SMA were investigated. As shown in Fig. 4, the mRNA expression of Ang-1, Ang-2, C-Tnl, VEGF, vWF and SMA were significantly increased by about 1.2, 2, 1.8, 3.5, 1.6 and 2.1 folds, respectively. In addition, the protein expression levels of Ang-1, Ang-2, C-Tnl, VEGF, vWF and SMA were significantly increased by about 1.2, 1.4, 1.9, 3.6, 1.5 and 1.8 folds, respectively (Fig. 5).

\section{Measuring Cytokine Secretion Of BM-resident C-kit Cells By ELISA}

The data of the present study demonstrate that in the presence of LC, BM- resident c-kit ${ }^{+}$cells express and secrete a variety of growth factors, which stimulate the cardiomyogenesis. Cytokines derived cultured media (IL-6, IGF-1, TGF- $\beta$, and VEGF) from two groups of cells; group I (control group without any LC treatment) and group II (experimental group with LC treatment) were assayed using ELISA sandwich technique. Results from ELISA revealed that the secretion of IL-6, IGF-1, TGF- $\beta$, and VEGF significantly increased in group II (experimental group with LC treatment) compared to group I (control group without any LC treatment) (Fig. 6) ( ${ }^{*} P<0.05$ and $\left.{ }^{*} * \mathrm{P}<0.001\right)$. In the other words, an increase $3.39,1.63,1.79$ and 2 times of IL-6, IGF-1, TGF- $\beta$, and VEGF was observed in the culture media of experimental group compared to control group, respectively.

\section{Discussion}

Following the first published paper reporting BM-resident c-kit ${ }^{+}$cells capability in cardiomyocytes regeneration in the mouse model infarcted heart; various publications with elaborated affairs showed the effect of these cells on myocardial healing [19]. Also, the ability of BM-resident c-kit ${ }^{+}$cells in generating specialized types of heart cells during cardiogenesis, have been shown [20]. In addition, some studies have focused on and examined other cell populations including BM BM-MNCs, mesenchymal stem cells (MSCs), EPCs, and BM-resident CD133+ cells [21]. The use of separate pools of BM cells has made the 
comparison among studies rather intricate [22]. In spite of this, an agreement has been reached on the mechanisms of actions of various BM cell classes. It is well known that the majority of BM cells are the sources of many growth factors and cytokines affecting paracrine cardiac stem cells and vascular cells [21]. Considering all these interpretations, the potential role of the subset of BM-resident c-kit ${ }^{+}$cells in myocardial regeneration remains controversial. One study suggested that BM-resident c-kit + cells cannot be adopted to a cardiac phenotype, and hematopoietic identity of c-kit + cells is preserved [23]. Therefore, comprehension of the base of these controversial results is important to recognize the clinical function of BM-resident c-kit + cells. Also, finding some effective and suitable agents such as vitamins and antioxidants to increase cardiomyogenic differentiation potential and cell viability of these progenitor cells could promote cardiomyocyte function in clinical. Based on the mentioned above, in this study, LC was used as natural antioxidant that useful for cardiac function. The potential therapeutic effects of LC and its derivatives in the cardiovascular diseases treatment have been considered since the mid-1980s [24]. For the first time, Spagnoli et al. (1982) reported a low LC concentration in the heart of patients who died of MI, so it was shown that LC and its analogues may be beneficial in the prevention of damage to the heart after an ischemic [25]. In the following, lliceto et al. (1995) indicated that LC treatment reduced necrosis and apoptosis of myocardiocytes within the left ventricle [26]. The study of Sack et al. (1996) showed recovery of heart arrhythmia following treatment with LC [27]. In another study, Pauly and Pepine (2003) demonstrated that supplementation with LC has a specified protective effect through attenuated oxygen deficiency and reactive oxygen species (ROS) generation that result in ameliorative impact on ventricular functional impairment and cardiac oxygen deficiency [28]. In another study by Ogawa et al. (2008), it was shown that LC treatment induced protective anti-oxidative and anti-inflammatory effects and decreased myocardial dysfunction in choline-deficient rats [29]. In the present study, $0.2 \mathrm{mM}$ was used as the final concentration of LC. For recognition of LC effective concentration and to examine the viability of BM-resident c-kit ${ }^{+}$cells, we used MTT assay and it became clear that under the 0.1 and $0.2 \mathrm{mM}$ LC concentrations no significant effect on the viability of BM-resident c-kit + cells was seen. To explore the LC effect mechanism on cardiomyogenic differentiation of BM-resident c-kit ${ }^{+}$cells at the cellular and molecular level, we explored the gene and protein expression of Ang-1, Ang-2, C-Tnl, VEGF, VWF and SMA as cardiac differentiation markers, as well as secreted cytokines such as IL-6, IGF-1, TGF- $\beta$, and VEGF in response to LC treatment. The results of this study showed that in group II (experimental group with LC treatment), LC promoted the mRNA expression as well as protein expression of Ang-1, Ang2, C-Tnl, VEGF, vWF and SMA as compared with group I (control group without any LC treatment). On the other words, in the present study we showed that $0.2 \mathrm{Mm} \mathrm{LC}$ enhances the cardiac differentiation of BMresident c-kit ${ }^{+}$cells by the expression of VEGF and vWF as endothelial cell markers, SMA as smooth muscle cell marker and Troponin T as cardiomyocyte marker. The results obtained by Kubo et al. (2009) provide evidence that $\mathrm{BM}$-resident $\mathrm{c}-\mathrm{kit}^{+}$cells have the ability to transdifferentiate into functional cardiac myocytes when co-cultured with neonatal rat ventricular myocytes (NRVM). They showed that in the presence of NRVM, BM-resident c-kit ${ }^{+}$cells could express the actinin and a-tropomyosin [30]. Because of angiogenesis is an important aspect of repair tissue, we also investigated the angiogenic factors. As previously proved, normal c-kit function in cardiomyogenesis was associated with increase in VEGF that 
was accompanied by a reversal of Ang-2/Ang-1ratio [31]. In another part of the result section, we explained that LC could increase the gene and protein expression of Ang-1 and Ang-2. Ang-2 is critical in angiogenesis because it blocks the tonic quiescent signal that is delivered by Ang-1. Increased Ang2/Ang-1 ratio potentiates the endothelial cells responsiveness to VEGF and promotes blood vessel [32]. We also observed that the increase in the expression of cardiac markers correlated with the increasing presence of IL-6, IGF-1, TGF- $\beta$, and VEGF. Importantly, it was indicated that treatment of BM-resident c-kit ${ }^{+}$ cells with LC can induce cardiac differentiation and angiogenesis, suggesting that this result may be due to cytokine secretion induction. In addition to differentiation capacity of BM stem and progenitor cells toward cardiac cell lineages, releasing some cytokines and paracrine factors which have anti-remodeling, anti-apoptotic and anti-inflammatory effects have become its promising candidates for regenerative medicine [33]. In the other words, it was reported that under heart tissue ischemic and hypoxic conditions, stem and progenitor cells can release cytokines and growth factors that most important of them are as follows: TGF- $\beta$, IL-6, VEGF, angiopoietin (Ang)-1, IGF, fibroblast growth factor (FGF)-2 and TNF-a, among others. These secreted cytokines exert important anti-remodeling, anti-apoptosis and anti-inflammatory effects in a paracrine manner cytokines which play pivotal roles in stem cell-related cardiac repair mechanisms [34]. Among the mentioned cytokines, TGF- $\beta$, IL-6, IGF-1 and VEGF are the most widely regulator in cardiomyocyte regeneration $[35,36]$. In one study, Bujak and Frangogiannis (2007) reported that after MI the TGF- $\beta$ was upregulated especially in the infarct border zone. This upregulation was associated with expression of Smad 2, 3 and 4 pathway [37]. In another study, Rouhi et al. (2013) indicated that autologous serum promoted cardiomyogenesis of rat BM-resident stem cells in the presence of TGF- $\beta$ [38]. Various studies were done on the fundamental effects of IL-6 family as key regulatory role in cardiac regeneration [35]. In a preliminary study by Freed et al. (2005), it was shown that upregulation of cardiotrophin-1 (CT-1) as a member of the IL- 6 cytokine family inhibited the fibroblast proliferation in the infarcted myocardium zone [39]. In previous study by Tang et al. (2018), it was demonstrated that IL-6 as a pro-inflammatory cytokine has good effects on improving cardiac function in mice model with cardiac injury [40]. Among the mechanisms resulting in beneficial effects from stem cell transplantation in heart regeneration it is obvious that neovascularization may be considered which regulated by a variety of cytokines, such as the VEGF, FGF etc [41]. In one investigation by Mathison et al. (2012), it was indicated that pretreatment of cardiac scars with gene transfer of VEGF boosted the transdifferentiation of fibroblasts into cardiomyocytes in rat animal model [42]. Also in another study, Ye et I. (2013) reported that VEGF as neovascularization key factor is required for effective cardiomyocyte differentiation of human induced pluripotent stem cells [43]. According to the aforementioned results, interestingly, we are the first to report that $0.2 \mathrm{mM} \mathrm{LC}$ as endogenous antioxidant agent could induce the cardiac differentiation of BM-resident c-kit ${ }^{+}$cells via increasing the cardiac markers expression Ang-1, Ang-2, C-TnI, VEGF, vWF and SMA. Its effects may be due to secreted cytokines IL-6, IGF-1, TGF- $\beta$ and VEGF.

\section{Conclusion}


In conclusion, this research indicated that $0.2 \mathrm{mM} \mathrm{LC}$ could promote the gene and protein expression of cardiac- related markers in c-kit ${ }^{+}$stem/progenitor cells, which are correlated with the presence of cytokines IL-6, IGF-1, TGF- $\beta$, and VEGF. As tyrosine kinase activity to be critical for the in vitro functional cardiomyogenic differentiation of c-kit ${ }^{+}$stem/progenitor cells, examining the c-kit receptor expression via tyrosine kinase activity assay is suggested for future studies.

\section{Materials And Methods}

\section{Isolation of rat BM-resident c-kit ${ }^{+}$cells}

$\mathrm{C}^{-k \mathrm{kit}^{+}}\left(\mathrm{CD} 117^{+}\right)$cells were isolated from BM of About 8 (5- to 8-week-old) rats by positive selection with anti-CD117 MicroBeads. Rats were euthanized and mononuclear cells (MNCs) were isolated as previously reported by Fathi et al. (2019) [44]. The isolated MNCS was incubated with $100 \mu$ of CD117 ${ }^{+}$micro beads (Miltenyi Biotec, Germany; Cat no: 130-091-224) for 30 minutes. Thereafter, re-suspended cells were passed through one LS MACS column (Miltenyi Biotec, Germany) and enriched CD117 ${ }^{+}$cells were retrieved by flushing the column [45].

\section{Purity Assessment Of BM-resident C-kit Cells}

Purity assessment of enriched cells was done by flow cytometry. Briefly, approximately $20 \times 10^{4}$ enriched BM-resident c-kit ${ }^{+}$cells were incubated with $5 \mu$ of FITC-conjugated antibody CD117 (c-kit) (Biocompare, Lifespan BioSciences, USA) ( $\left.1 \mu \mathrm{g} / 10^{6} \mathrm{cells}\right)$ for $30 \mathrm{~min}$ on ice and subjected to fluorescence activated cell sorter (FACS) instrument (Becton Dickinson Franklin Lakes, USA) [44]. The output data were processed with FlowJo software version X.0.7. In addition to flow cytometry, immunocytochemistry (ICC) was done. The protocols used for ICC was described below in the immunofluorescence staining. Also, the antibody used for ICC was PE-conjugated c-Kit/CD117 antibody (LS-C78828, Lifespan Biosciences, Inc., USA).

\section{Cardiomyogenic Differentiation Of BM-resident C-kit Cells}

Cardiomyogenic differentiation of BM-resident c-kit ${ }^{+}$cells were induced by cardiomyocyte differentiation

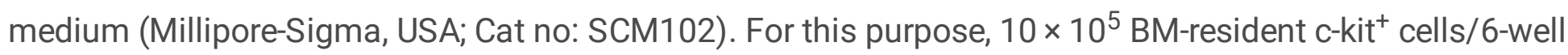
plates were cultured in cardiomyocyte differentiation medium for 14 days. The medium was refreshed with fresh cardiomyocyte differentiation medium three times per week. Cardiomyocyte induction was confirmed by immunocytochemistry (ICC).

\section{Immunofluorescence Staining}


ICC was done as previously reported by Fathi and Farahzadi (2018) [46]. In brief, a total of $4 \times 10^{3} \mathrm{BM}$ resident c-kit ${ }^{+}$cells were plated in chamber slide containing cardiomyocyte differentiation medium for 14 days. The control group was assessed in the absence of cardiomyocyte differentiation medium. At the end of 14 th days incubation, the cells were fixed in $4 \%$ paraformaldehyde for $30-60$ min at $25^{\circ} \mathrm{C}$. In the following, the cells were incubated 16 hours at $4^{\circ} \mathrm{C}$ with mAbs against a-actinin and desmin (all from cardiomyocyte characterization kit, Chemicon International, USA; Cat no: SCR059) in PBS. The cells were then incubated with a goat anti-mouse IgG-PE as secondary antibody (sc-3738, Santa Cruz Biothecnology, USA) for $2 \mathrm{~h}$. Then, cells were washed with PBS and nuclei were stained with DAPI at 30 sec. After washing, the fluorescent cells were visualized under a fluorescence microscope.

\section{Cell Proliferation Assay}

The MTT test was done to define proper concentration of LC. BM-resident c-kit ${ }^{+}$cells were seeded at $2 \times$ $10^{3}$ cells/wells. In the following, LC was used at final concentrations of $0.1,0.2$ and $0.4 \mathrm{mM}$ and incubated under the same culture conditions for 7,14 and 21 days. At the end of incubation time $(7,14$ and 21 days), the culture media was removed and MTT dye solution was added for $4 \mathrm{~h}$. At the end of $4 \mathrm{~h}$, the MTT solution was removed and formazan crystals were dissolved in DMSO. The optical density of each well was measured at a wavelength of $570 \mathrm{~nm}$ by an ELISA reader (Labsystems, Helsinki, Finland) [18].

In this study, the cells were divided two groups: group I as control group (cardiomyogenic differentiated BM-resident c-kit ${ }^{+}$cells without any LC treatment) and group II as experimental group (cardiomyogenic differentiated BM-resident c-kit ${ }^{+}$cells with LC treatment). The treatment period in both control and experimental groups was 14 days.

\section{Western Blot Analysis For Protein Expression Assessment}

BM-resident c-kit ${ }^{+}$cells from both control and experimental groups were collected and protein was extracted as previously explained by Valipour et al. (2018) [47]. $50 \mu \mathrm{g}$ of each cell protein sample was electrophoresed on $12 \%$ polyacrylamide slab gels and transferred to poly vinylidene difluoride (PVDF) membrane. In the following, the membranes were incubated overnight at $4{ }^{\circ} \mathrm{C}$ with primary polyclonal antibodies (1:1000) against $\beta$-actin (sc-69879), Angiopoietin-1 (Ang-1) (sc-517593), Angiopoietin-2 (Ang2) (sc-74403), Cardiac Troponin-I (C-Tnl) (sc-133117), VEGF (sc-7269), von Willebrand Factor (vWF) (sc365712) and SMA (sc-53015), and were incubated with goat anti-mouse secondary antibody for 60 min at $25^{\circ} \mathrm{C}$. Next, the membranes were washed and protein bands were detected using ECL with X-ray film. The intensity of protein bands was measured by Image 1.6 software. All used antibodies were obtained from Santa Cruz Biotechnology, USA. 


\section{Quantitative Real Time-PCR}

The BM-resident c-kit ${ }^{+}$cells from both control and experimental groups were collected. Next, total RNA was extracted and cDNA was synthesized using molecular kits (Yekta Tajhiz Azma, IRAN). The mRNA expressions of target genes included Ang-1, Ang-2, C-Tnl, VEGF, vWF, SMA and $\beta$-actin. Fluorescence data was calculated in relation to $\beta$-actin CT values by the $2^{-\triangle \Delta C T}$ method. Primers (Table 1 ) were designed using Oligo 7 v.7.52 software [18].

Table 1

Primer sequences used for the Real time-PCR assays

\begin{tabular}{|c|c|c|c|}
\hline No. & Gene & Primer pair sequence $\left(5^{\prime}-3^{\prime}\right)$ & Product length (bp) \\
\hline \multirow[t]{2}{*}{ NM_001146.5 } & \multirow[t]{2}{*}{ Ang-1 } & СTCGCTGCCATTCTGACTCAC & \multirow[t]{2}{*}{136} \\
\hline & & GACAGTTGCCATCGTGTTCTG & \\
\hline XM_017013318.1 & Ang-2 & $\begin{array}{l}\text { TCTTGGCCGCAGCCTATAAC } \\
\text { TGCTGGACCTGATATTGCTTCT }\end{array}$ & 73 \\
\hline XM_006716677.4 & $C-T n I$ & $\begin{array}{l}\text { GCAGGTGAAGAAGGAGGACA } \\
\text { CGATATTCTTGCGCCAGTC }\end{array}$ & 139 \\
\hline NM_001204384.1 & $V E G F$ & $\begin{array}{l}\text { ATCACGAAGTGGTGAAGTTC } \\
\text { TGCTGTAGGAAGCTCATCTC }\end{array}$ & 117 \\
\hline NM_000552.4 & $v W F$ & $\begin{array}{l}\text { GCAGTGGAGAACAGTGGTG } \\
\text { GTGGCAGCGGGCAAAC }\end{array}$ & 134 \\
\hline NM_001613.4 & $S M A$ & $\begin{array}{l}\text { ATCACCAACTGGGACGACAT } \\
\text { CATACATGGCTGGGACATTG }\end{array}$ & 175 \\
\hline NM_001101.5 & $\beta$-actin & $\begin{array}{l}\text { TCCTCTCCCAAGTCCACACAGG } \\
\text { GGGCACGAAGGCTCATCATTC }\end{array}$ & 131 \\
\hline
\end{tabular}

\section{Cytokine Measuring By ELISA}

Culture media was collected from each group including, control group without any LC treatment, and experimental group with LC treatment. ELISA was performed according to the manufactures guidelines (R\&D Systems, China). In brief, a 96-well plate was coated with detection Reagent $A$ at $4^{\circ} \mathrm{C}$ for 16 hours. Then, $50 \mu$ l of cell culture media was added into the 96 -well plate, which had been coated with mouse interleukin (IL)-6, insulin-like growth factor (IGF-1), transforming growth factor- $\beta$ (TGF- $\beta$ ) and vascular endothelial growth factor (VEGF) antibodies, and detected via the ELISA sandwich technique.

\section{Statistical analysis}


The results from Figs. 3 and 6 were analyzed using two-way ANOVA followed by Sidak's multiple comparisons test. The results from Figs. 4 and 5 were analyzed using Unpaired t-test. The statistical significance was determined at $p<0.05$ by Graph Pad Prism version 6.01. All experimental procedures were repeated for three times $(n=3)$.

\section{Declarations}

\section{Ethics approval and consent to participate}

Ethical consent was approved by an ethics committee at Tabriz University of Medical Sciences, Tabriz, Iran (Ethic Code No: IR.TBZMED.REC.1396.607) in accordance with the guidelines of Helsinki-Ethical Principles.

\section{Consent for publication}

All authors have contributed to this study and approve its submission.

\section{Availability of data and materials}

The data sets used and/or analyzed during the current study are available from the corresponding author on reasonable request.

\section{Competing interests}

The authors declare that they have no conflict of interest.

\section{Funding}

This project was supported by a research grant from the University of Tabriz, Tabriz, Iran (Grant No. S/813).

\section{Author contributions}

Ezzatollah Fathi as the executive of the project had main contribution in conception and design, data analysis and manuscript writing; Raheleh Farahzadi as main colleague involved in performance of experiments, data analysis and manuscript writing, Ilja Vietor provided some materials needed for this project, and Sara Javanmardi performed surgery on rats; all authors approved the final version of the article.

\section{Acknowledgements}

This project was supported by a research grant from the University of Tabriz, Tabriz, Iran (Grant No. S/813).

\section{References}


1. Wencker D, Chandra M, Nguyen K, Miao W, Garantziotis S, Factor SM, et al. A mechanistic role for cardiac myocyte apoptosis in heart failure. J Clin Investig. 2003;111(10):1497-504.

2. Bastami M, Choupani J, Saadatian Z, Zununi Vahed S, Mansoori Y, Daraei A, et al. miRNA polymorphisms and risk of cardio-cerebrovascular diseases: a systematic review and meta-analysis. Int J Mol Sci. 2019;20(2):293.

3. Isner JM, Asahara T. Angiogenesis and vasculogenesis as therapeutic strategies for postnatal neovascularization. J Clin Investig. 1999;103(9):1231-6.

4. Vahed SZ, Aghaee-Bakhtiari SH, Daraei A, Saadatian Z, Kafil HS, Yousefi B, et al: Expression pattern of miR-21, miR-25 and PTEN in peripheral blood mononuclear cells of patients with significant or insignificant coronary stenosis. Gene. 2019.

5. Miyamoto S, Kawaguchi N, Ellison GM, Matsuoka R, Shin'oka T, Kurosawa H. Characterization of long-term cultured c-kit + cardiac stem cells derived from adult rat hearts. Stem Cells Dev. 2010;19(1):105-16.

6. Traister A, Patel R, Huang A, Patel S, Plakhotnik J, Lee JE, et al. Cardiac regenerative capacity is ageand disease-dependent in childhood heart disease. PloS one. 2018;13(7):e0200342.

7. Ishigami M, Masumoto H, Ikuno T, Aoki T, Kawatou M, Minakata K, et al. Human iPS cell-derived cardiac tissue sheets for functional restoration of infarcted porcine hearts. PloS one. 2018;13(8):e0201650.

8. Jackson R, Mount S, Ye B, Mayfield AE, Chan V, Boodhwani M, et al. Isolation of human explant derived cardiac stem cells from cryopreserved heart tissue. PloS one. 2017;12(4):e0176000.

9. Mohsin S, Siddiqi S, Collins B, Sussman MA. Empowering adult stem cells for myocardial regeneration. Circulation research. 2011;109(12):1415-28.

10. Nussbaum J, Minami E, Laflamme MA, Virag JA, Ware CB, Masino A, et al. Transplantation of undifferentiated murine embryonic stem cells in the heart: teratoma formation and immune response. FASEB J. 2007;21(7):1345-57.

11. Jeevanantham V, Afzal MR, Zuba-Surma EK, Dawn B: Clinical trials of cardiac repair with adult bone marrow-derived cells. In: Cellular Cardiomyoplasty. Springer; 2013: 179-205.

12. Honold J, Fischer-Rasokat U, Seeger FH, Leistner D, Lotz S, Dimmeler S, et al. Impact of intracoronary reinfusion of bone marrow-derived mononuclear progenitor cells on cardiopulmonary exercise capacity in patients with chronic postinfarction heart failure. Clin Res Cardiol. 2013;102(9):619-25.

13. Matuszczak S, Czapla J, Jarosz-Biej M, Wiśniewska E, Cichoń T, Smolarczyk R, et al. Characteristic of C-Kit + progenitor cells in explanted human hearts. Clin Res Cardiol. 2014;103(9):711-8.

14. Van Berlo JH, Kanisicak O, Maillet M, Vagnozzi RJ, Karch J, Lin S-CJ, et al. C-kit + cells minimally contribute cardiomyocytes to the heart. Nature. 2014;509(7500):337.

15. Abozguia K, Shivu GN, Ahmed I, Phan T, Frenneaux M. The heart metabolism: pathophysiological aspects in ischaemia and heart failure. Curr Pharm Design. 2009;15(8):827-35. 
16. Mingorance C, Rodríguez-Rodríguez R, Justo ML, de Sotomayor M, Herrera MD. Critical update for the clinical use of L-carnitine analogs in cardiometabolic disorders. Vasc Health Risk Manag. 2011;7:169.

17. Zhang L, Keung W, Samokhvalov V, Wang W, Lopaschuk GD. Role of fatty acid uptake and fatty acid $\beta$-oxidation in mediating insulin resistance in heart and skeletal muscle. Biochimica et Biophysica Acta (BBA)-Molecular and Cell Biology of Lipids. 2010; 1801(1):1-22.

18. Farahzadi R, Mesbah-Namin SA, Zarghami N, Fathi E. L-carnitine effectively induces hTERT gene expression of human adipose tissue-derived mesenchymal stem cells obtained from the aged subjects. International journal of stem cells. 2016;9(1):107.

19. Orlic D, Kajstura J, Chimenti S, Jakoniuk I, Anderson SM, Li B, et al. Bone marrow cells regenerate infarcted myocardium. Nature. 2001;410(6829):701.

20. Matsuda A, Ogórek B, Ferreira-Martins Jo, Cappetta D, Signore S, D'Amario D, et al: The Embryonic Heart Contains Resident C-Kit-Positive Cardiac Stem Cells. In.: Am Heart Assoc; 2011.

21. Afzal MR, Samanta A, Shah ZI, Jeevanantham V, Abdel-Latif A, Zuba-Surma EK, et al. Adult bone marrow cell therapy for ischemic heart disease: evidence and insights from randomized controlled trials. Circulation research. 2015;117(6):558-75.

22. van der Spoel TI, Jansen of Lorkeers SJ, Agostoni P, van Belle E, Gyöngyösi M, Sluijter JP, et al. Human relevance of pre-clinical studies in stem cell therapy: systematic review and meta-analysis of large animal models of ischaemic heart disease. Cardiovascular research. 2011;91(4):649-58.

23. Balsam LB, Wagers AJ, Christensen JL, Kofidis T, Weissman IL, Robbins RC. Haematopoietic stem cells adopt mature haematopoietic fates in ischaemic myocardium. Nature. 2004;428(6983):668.

24. PAULSON DJ, TRAXLER J, SCHMIDT M, NOONAN J, SHUG AL. Protection of the ischaemic myocardium by L-propionylcarnitine: effects on the recovery of cardiac output after ischaemia and reperfusion, carnitine transport, and fatty acid oxidation. Cardiovascular research. 1986;20(7):53641.

25. Spagnoli LG, Corsi M, Villaschi S, Palmieri G, Maccari F. Myocardial carnitine deficiency in acute myocardial infarction. The Lancet. 1982;319(8286):1419-20.

26. Iliceto S, Scrutinio D, Bruzzi P, D'Ambrosio G, Boni L, Di Biase M, et al. Effects of L-carnitine administration on left ventricular remodeling after acute anterior myocardial infarction: the LCarnitine Ecocardiografia Digitalizzata Infarto Miocardico (CEDIM) Trial. J Am Coll Cardiol. 1995;26(2):380-7.

27. Sack MN, Rader TA, Park S, Bastin J, McCune SA, Kelly DP. Fatty acid oxidation enzyme gene expression is downregulated in the failing heart. Circulation. 1996;94(11):2837-42.

28. Pauly DF, Pepine CJ. The role of carnitine in myocardial dysfunction. American journal of kidney diseases. 2003;41:35-43.

29. Ogawa T, Veinot JP, Kuroski de Bold ML, Georgalis T, de Bold AJ. Angiotensin II receptor antagonism reverts the selective cardiac BNP upregulation and secretion observed in myocarditis. Am J Physiol Heart Circ Physiol. 2008;294(6):H2596-603. 
30. Kubo H, Berretta RM, Jaleel N, Angert D, Houser SR. c-Kit + Bone Marrow Stem Cells Differentiate into Functional Cardiac Myocytes. Clin Transl Sci. 2009;2(1):26-32.

31. Fazel S, Cimini M, Chen L, Li S, Angoulvant D, Fedak P, et al. Cardioprotective c-kit + cells are from the bone marrow and regulate the myocardial balance of angiogenic cytokines. $\mathrm{J}$ Clin Investig. 2006;116(7):1865-77.

32. Hanahan D. Signaling vascular morphogenesis and maintenance. Science. 1997;277(5322):48-50.

33. Toth KG, McKay BR, De Lisio M, Little JP, Tarnopolsky MA, Parise G. IL-6 induced STAT3 signalling is associated with the proliferation of human muscle satellite cells following acute muscle damage. PloS one. 2011;6(3):e17392.

34. Duran JM, Makarewich CA, Sharp TE, Starosta T, Zhu F, Hoffman NE, et al. Bone-derived stem cells repair the heart after myocardial infarction through transdifferentiation and paracrine signaling mechanisms. Circulation research. 2013;113(5):539-52.

35. Li N, Wang C, Jia L, Du J. Heart regeneration, stem cells, and cytokines. Regenerative medicine research. 2014;2(1):6.

36. Park JS, Chu JS, Tsou AD, Diop R, Tang Z, Wang A, et al. The effect of matrix stiffness on the differentiation of mesenchymal stem cells in response to TGF- $\beta$. Biomaterials. 2011;32(16):392130 .

37. Bujak M, Frangogiannis NG. The role of TGF- $\beta$ signaling in myocardial infarction and cardiac remodeling. Cardiovascular research. 2007;74(2):184-95.

38. Rouhi L, Kajbafzadeh AM, Modaresi M, Shariati M, Hamrahi D: Autologous serum enhances cardiomyocyte differentiation of rat bone marrow mesenchymal stem cells in the presence of transforming growth factor- $\beta 1$ (TGF- $\beta 1$ ). In Vitro Cellular \& Developmental Biology-Animal. 2013; 49(4):287-294.

39. Freed DH, Cunnington RH, Dangerfield AL, Sutton JS, Dixon IM. Emerging evidence for the role of cardiotrophin-1 in cardiac repair in the infarcted heart. Cardiovasc Res. 2005;65(4):782-92.

40. Tang P, Ma S, Dong M, Wang J, Chai S, Liu T, et al. Effect of interleukin- 6 on myocardial regeneration in mice after cardiac injury. Biomed Pharmacother. 2018;106:303-8.

41. Boomsma RA, Geenen DL. Mesenchymal stem cells secrete multiple cytokines that promote angiogenesis and have contrasting effects on chemotaxis and apoptosis. PloS one. 2012;7(4):e35685.

42. Mathison M, Gersch P, Nasser R, Lilo A, Korman S, Fourman M. M et al: In vivo cardiac cellular reprogramming efficacy is enhanced by angiogenic preconditioning of the infarcted myocardium with vascular endothelial growth factor. Journal of the American Heart Association. 2012;1(6):e005652.

43. Ye L, Zhang S, Greder L, Dutton J, Keirstead SA, Lepley M, et al. Effective cardiac myocyte differentiation of human induced pluripotent stem cells requires VEGF. PloS one. 2013;8(1):e53764.

44. Fathi E, Farahzadi R, Valipour B, Sanaat Z. Cytokines secreted from bone marrow derived mesenchymal stem cells promote apoptosis and change cell cycle distribution of K562 cell line as 
clinical agent in cell transplantation. PloS one. 2019;14(4):e0215678.

45. Czarna A, Sanada F, Matsuda A, Kim J, Signore S, Pereira JD, et al. Single-cell analysis of the fate of c-kit-positive bone marrow cells. NPJ Regenerative medicine. 2017;2(1):27.

46. Fathi E, Farahzadi R. Zinc Sulphate Mediates the Stimulation of Cell Proliferation of Rat Adipose Tissue-Derived Mesenchymal Stem Cells Under High Intensity of EMF Exposure. Biological trace element research. 2017.

47. Valipour B, Mohammadi SM, Abedelahi A, Maragheh BFA, Naderali E, Dehnad A, et al. Culture filtrate ether extracted metabolites from Streptomyces levis ABRIINW111 increased apoptosis and reduced proliferation in acute lymphoblastic leukemia. Biomed Pharmacother. 2018;108:216-23.

\section{Figures}

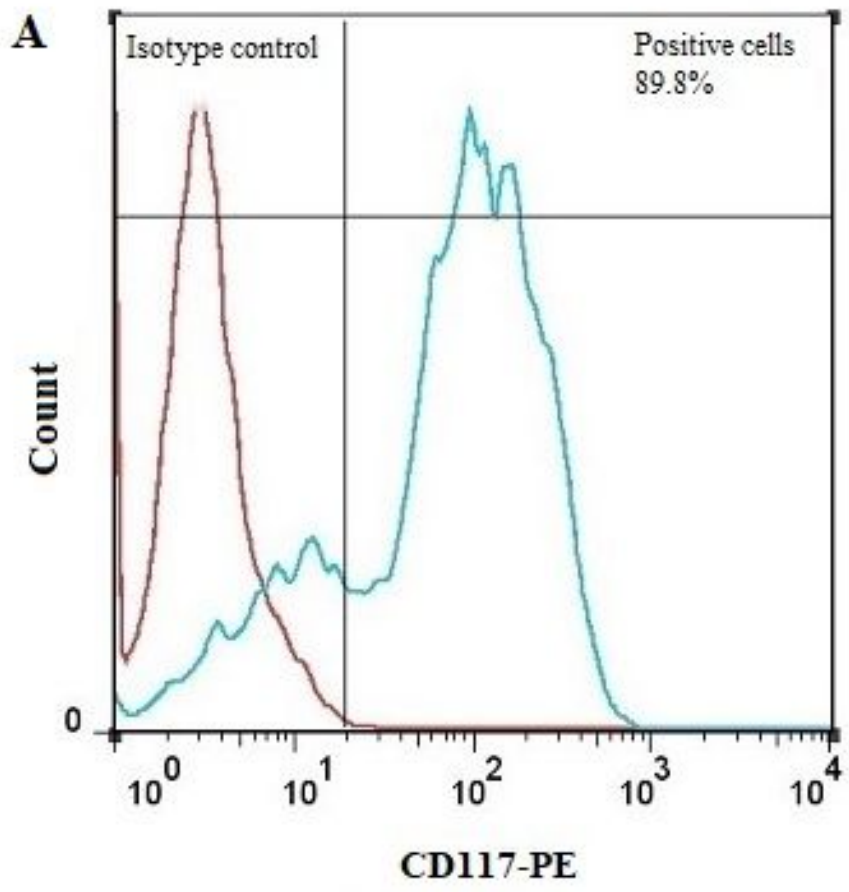

B

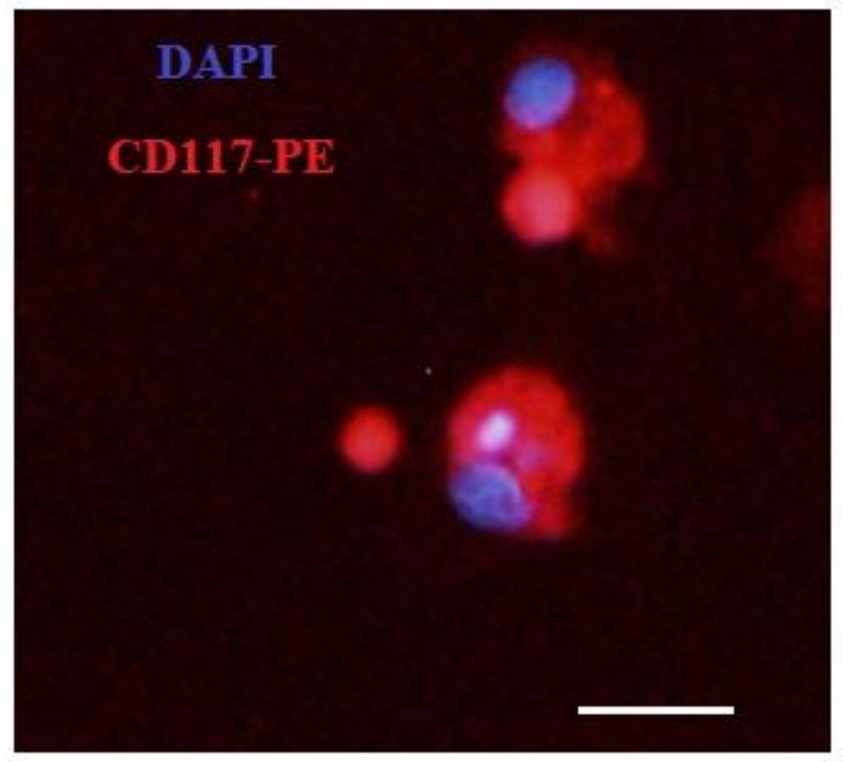

\section{Figure 1}

Characterization of isolated BM-resident c-kit+ cells by flow cytometry and immunofluorescence analyses. (A) Flow cytometry showed that more than $89 \%$ of cells were positive for CD117 (c-kit). Data are expressed as mean \pm SD. (B) Data confirmed the existence of CD117 (c-kit) indicated by positive color cells by immunofluorescence imaging; Blue = DAPI; Red = PE-conjugated CD117 (bar=20 $\mu \mathrm{m})$. 

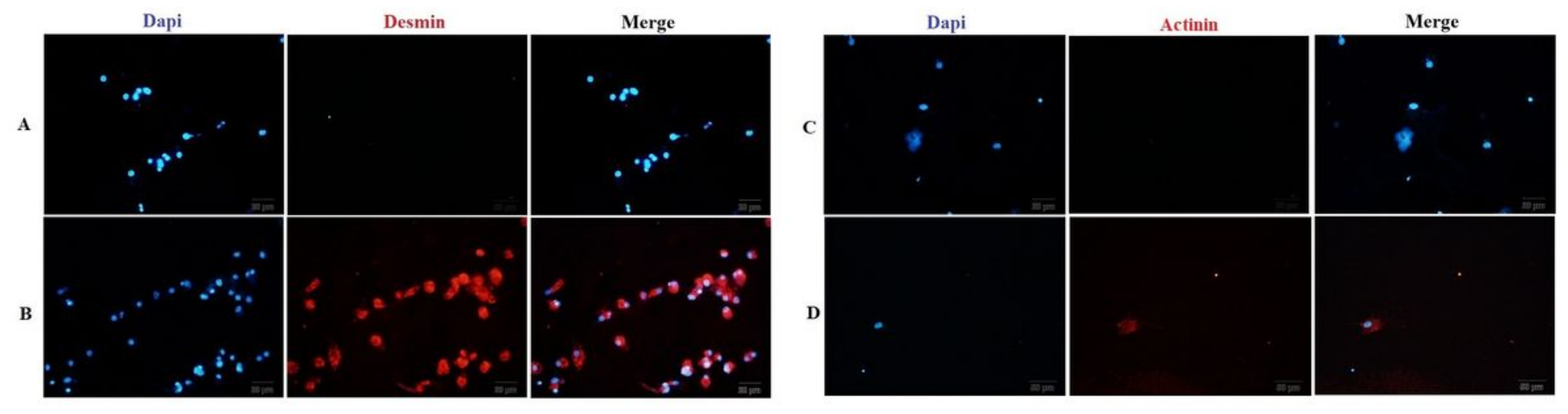

\section{Figure 2}

BM-resident c-kit+ cells differentiate into the cardiomyogenic lineage in vitro. $\mathrm{A}$ and $\mathrm{C}$ are negative controls (c-kit+ cells in the absence of cardiomyogenic differentiation), (B) Desmin (red)-positive and (D) Actinin (orange)-positive cells expressed in the c-kit+ cardiomyogenic differentiated cells; Nuclei were stained by DAPI in blue.

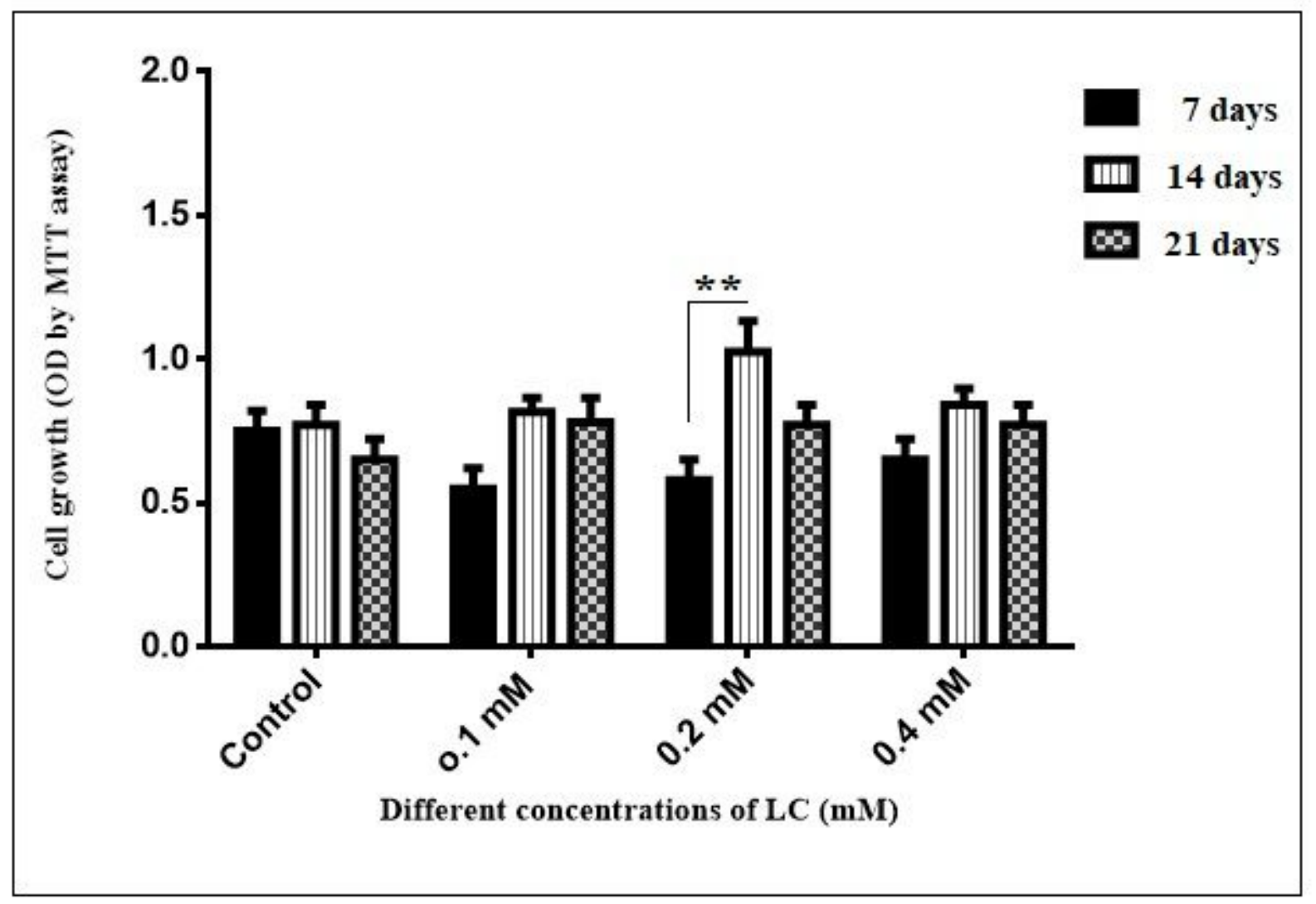

Figure 3

Growth and proliferation rates of BM- resident c-kit+ cells in the presence different concentrations of LC for 24, 48 and 72 hours, using MTT assay (** $₫ 0.01$ compared with control group). BM-resident c-kit+ cells were cultured at the density of $2 \times 103$ cells per well in the absence and in the presence of $0.1,0.2$ 
and 0.4 of LC, as described in MTT section. MTT dye solution was added when c-kit+ cells were cultured for 14 days. After $4 \mathrm{~h}$ incubation, culture medium was removed, DMSO was added and the optical density of each well was measured at a wavelength of $570 \mathrm{~nm}$. Data represent as the means \pm SE from three independent biological experiments. Two-way ANOVA followed by Sidak's multiple comparisons test was used to determine the significant difference among groups $(n=3)$.
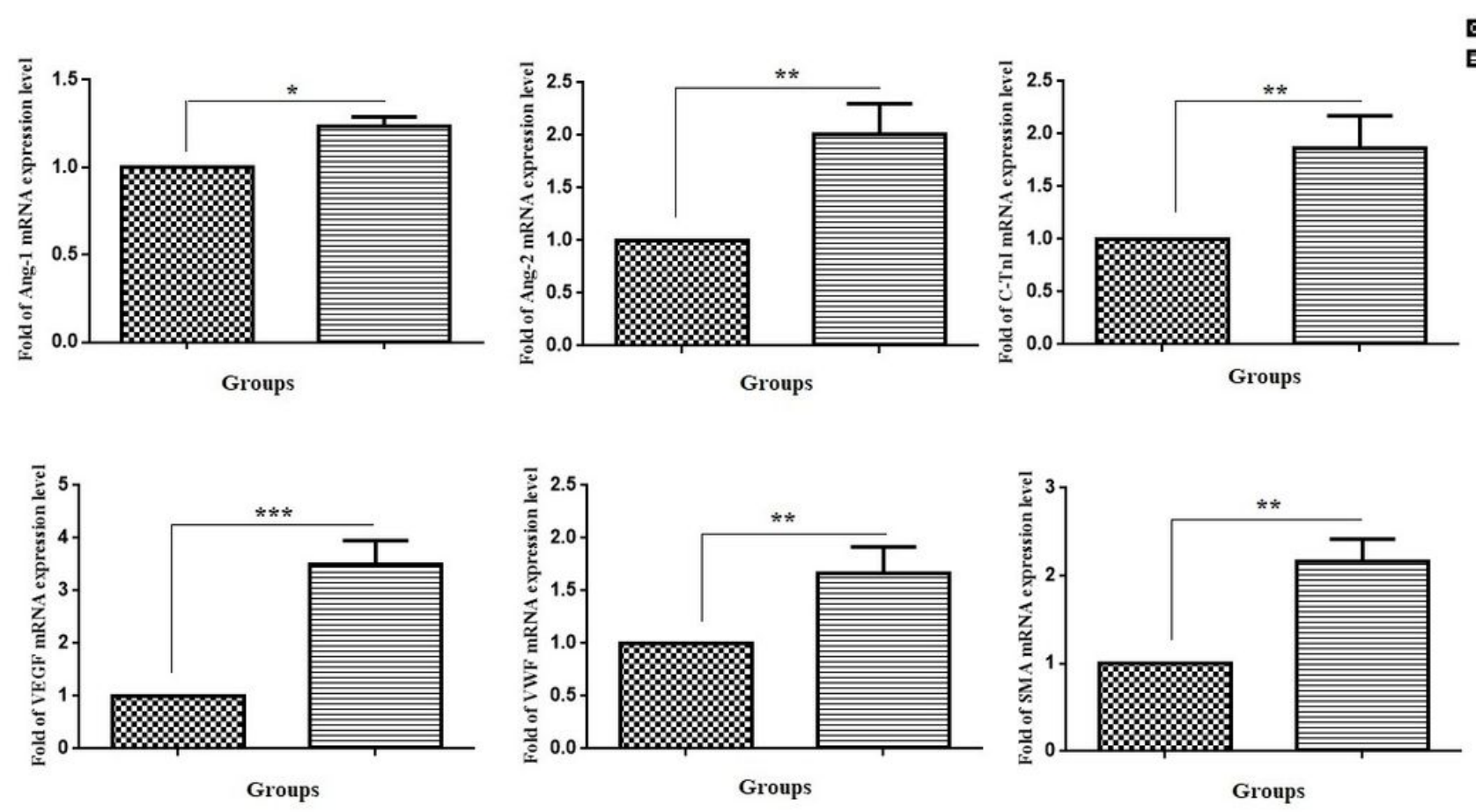

\section{Figure 4}

LC effect on Ang-1, Ang-2, C-Tnl, VEGF, vWF and SMA mRNA expression in BM- resident c-kit+ cells. Cells were cultured in 6-well plates at a concentration of 50×104 cells/well. RNA was extracted from cultured ckit+ cells in group I (control group without any LC treatment) and group II (experimental group with LC treatment) as described in methods section and was subjected to Real-time PCR assay; mean \pm SEM; $n=3 ; * P<0.05, * * P<0.01$ and ${ }^{* * *} P<0.001$. Data represent as the means $\pm S E$ from three independent biological experiments. Unpaired t-test was used to determine the significant difference among groups $(n=3)$. 

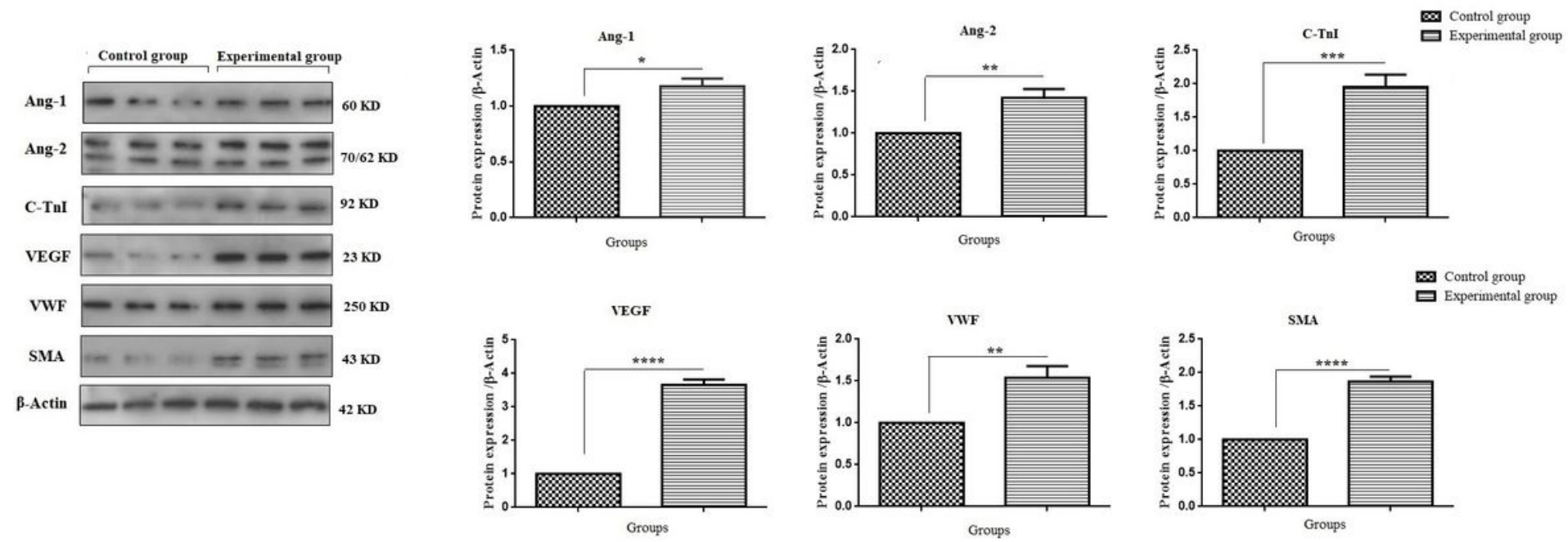

Control group Experimental group

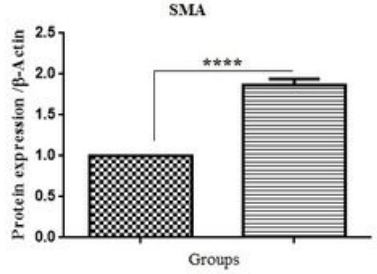

\section{Figure 5}

LC effect on Ang-1, Ang-2, C-Tnl, VEGF, vWF and SMA protein expression in BM- resident c-kit+ cells. Cells were cultured in 6-well plates at a concentration of 10×105 cells/well. Protein was extracted from cultured c-kit+ cells in group I (control group without any LC treatment) and group II (experimental group with LC treatment) as described in methods section and was subjected to western blotting; mean $\pm S E M ; n=3$; ${ }^{*} P<0.05,{ }^{*} P<0.01, * \star * P<0.001$ and ${ }^{*} * \star * P<0.0001$. Data represent as the means $\pm S E$ from three independent biological experiments. Unpaired t-test was used to determine the significant difference among groups $(n=3)$. 


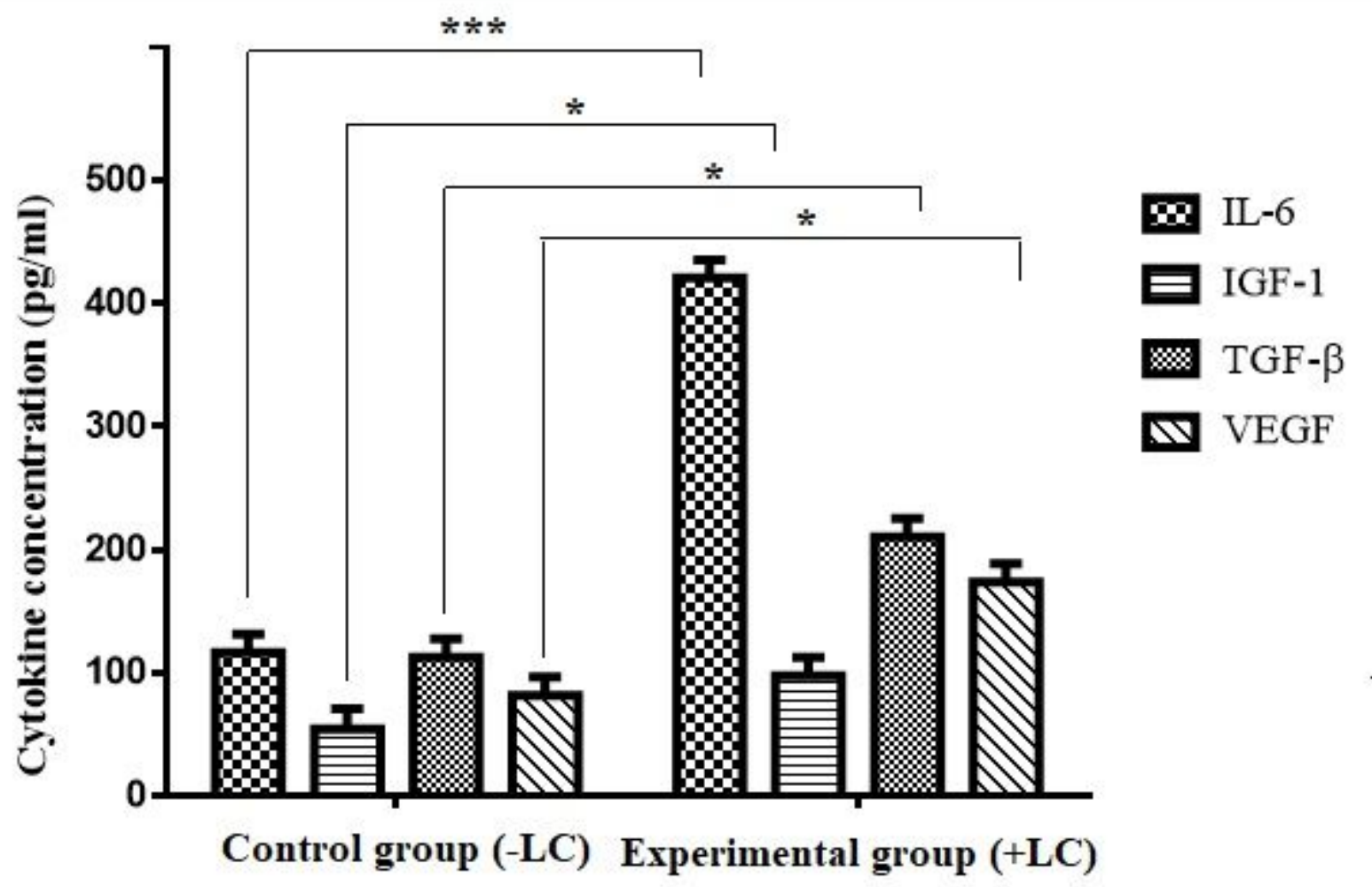

\section{Groups}

Figure 6

The secretion levels of cytokines IL-6, IGF-1, TGF- $\beta$ and VEGF from two groups; control (without any LC treatment) and experimental (with $0.2 \mathrm{mM} \mathrm{LC}$ treatment). ( ${ }^{\star} p<0.05$ and ${ }^{* \star *} p<0.001$; compared with control group). Data represent as the means $\pm S E$ from three independent biological experiments. Twoway ANOVA followed by Sidak's multiple comparisons test was used to determine the significant difference among groups $(n=3)$.

\section{Supplementary Files}

This is a list of supplementary files associated with this preprint. Click to download.

- GraphicalAbstract.jpg 